\title{
Fixed point theorems for monotone multi-valued mappings in partially ordered metric spaces
}

\author{
Jukrapong Tiammee and Suthep Suantai
}

\section{"Correspondence:}

suthep.s@cmu.ac.th

Department of Mathematics,

Faculty of Science, Chiang Mai

University, Chiang Mai, Thailand

\begin{abstract}
In this paper, we introduce two new types of monotone multi-valued mappings in partially ordered metric spaces and prove some fixed point theorems of those two types of mappings under some contraction conditions. Our main results extend many known results in the literature. Moreover, we also give an example which satisfies our main theorem but Nadler's theorem cannot be applied.
\end{abstract}

MSC: $47 \mathrm{H} 04 ; 47 \mathrm{H} 10$

Keywords: fixed point theorems; multi-valued mappings; partially ordered set; monotone mappings

\section{Introduction}

For a metric space $(X, d)$, we let $C B(X)$ and $\operatorname{Comp}(X)$ to be the set of all nonempty closed bounded subsets of $X$ and the set of all nonempty compact subsets of $X$, respectively.

Fixed point theorems of multi-valued mappings play extremely important roles in economics and engineering $[1,2]$, especially in game theory $[3,4]$. They can be used for proving the existence of Nash equilibria of a non-cooperative game. The first well-known theorem for multi-valued contraction mappings was given by Nadler [5] in 1967.

Theorem 1.1 ([5]) Let $(X, d)$ be a complete metric space and let $T$ be a mapping from $X$ into $C B(X)$. Assume that there exists $k \in[0,1)$ such that

$$
H(T x, T y) \leq k d(x, y) \quad \text { for all } x, y \in X .
$$

Then there exists $z \in X$ such that $z \in T z$.

The Nadler's fixed point theorem for multi-valued contractive mappings has been extended in many directions (see [2, 4-17]). Reich [18] proved the following fixed point theorem for multi-valued $\varphi$ contraction mappings.

Theorem 1.2 ([18]) Let $(X, d)$ be a complete metric space and let $T$ be a mapping from $X$ into $\operatorname{Comp}(X)$. Assume that there exists a function $\varphi:(0, \infty) \rightarrow[0,1)$ such that

$$
\lim _{r \rightarrow t+} \sup \varphi(r)<1 \quad \text { for each } t \in[0, \infty)
$$

O2014Tiammee and Suantai; licensee Springer. This is an Open Access article distributed under the terms of the Creative Commons Attribution License (http://creativecommons.org/licenses/by/2.0), which permits unrestricted use, distribution, and reproduction in any medium, provided the original work is properly cited. 
and

$$
H(T x, T y) \leq \varphi(d(x, y))(d(x, y)) \quad \text { for all } x, y \in X
$$

Then there exists $z \in X$ such that $z \in T z$.

The multi-valued mapping $T$ considered by Reich in Theorem 2 has compact value, that is, $T x$ is a nonempty compact subset of $X$ for all $x \in X$. In 1989, Mizoguchi and Takahashi [16] relaxed the compactness of value of $T$ to closed and bounded subsets of $X$. They proved the following theorem, which is a generalization of Nadler's theorem.

Theorem 1.3 ([16]) Let $(X, d)$ be a complete metric space and let $T: X \rightarrow C B(X)$. Assume that there exists a function $\varphi:(0, \infty) \rightarrow[0,1)$ such that

$$
\lim _{r \rightarrow t^{+}} \sup \varphi(r)<1 \quad \text { for each } t \in[0, \infty)
$$

and

$$
H(T x, T y) \leq \varphi(d(x, y))(d(x, y)) \quad \text { for all } x, y \in X
$$

Then there exists $z \in X$ such that $z \in T z$.

Recently, many fixed point theorems have been extended to partially ordered space (see $[2-4,8-16,19-22])$. Some fixed point theorems in partially ordered metric spaces can be applied to study a problem of ordinary differential equations. In 2004, Ran and Reurings [23] proved Banach's fixed point theorem in partially ordered metric spaces.

Theorem 1.4 ([23]) Let $X$ be a partially ordered set such that every pair $x, y \in X$ has a lower bound and upper bound. Furthermore, let $d$ be a metric on $T$ such that $(X, d)$ is a complete metric space. If $T$ is a continuous, monotone (i.e., either order-preserving or order-reversing) map from $X$ into $X$ such that

(1) there exists $c \in(0,1)$ such that

$$
d(T(x), T(y)) \leq c d(x, y) \quad \text { for all } x \geq y
$$

(2) there exists $x_{0} \in T x_{0}$ such that $x_{0} \leq T\left(x_{0}\right)$ or $x_{0} \geq T\left(x_{0}\right)$,

then $T$ has a unique fixed point $\bar{x}$. Moreover, for every $x \in X$,

$$
\lim _{n \rightarrow \infty} T^{n}(x)=\bar{x}
$$

In 2005, Nieto and Rodriguez-Lopez [24] extended the above result for a mapping $T$ without continuity.

Theorem 1.5 ([24]) Let $(X, \leq)$ be a partially ordered set and suppose that there exists a metric $d$ in $X$ such that $(X, d)$ is a complete metric space. Assume that $X$ satisfies

if a nondecreasing sequence $\left\{x_{n}\right\} \rightarrow x$ in $X$, then $x_{n} \leq x, \forall n$. 
Let $f: X \rightarrow X$ be a monotone nondecreasing mapping such that there exists $k \in[0,1)$ with

$$
d(f(x), f(y)) \leq k d(x, y), \quad \forall x \geq y .
$$

If there exists $x_{0} \in X$ with $x_{0} \leq f\left(x_{0}\right)$, then $f$ has a fixed point.

Motivated by these works, we are interested to define two types of monotone multivalued mappings in partially ordered metric spaces and prove some fixed point theorems of these mappings under some contraction conditions considered by Mizoguchi and Takahashi [16].

\section{Preliminaries}

Let $(X, d)$ be a metric space and $C B(X)$ be the set of all nonempty closed bounded subsets of $X$. For $x \in X$ and $A, B \in C B(X)$, define

$$
\begin{aligned}
& d(x, A)=\inf \{d(x, y): y \in A\}, \\
& \delta(A, B)=\sup \{d(x, B): x \in A\} .
\end{aligned}
$$

Denote $H$ the Hausdorff metric induced by $d$, that is,

$$
H(A, B)=\max \left\{\sup _{u \in A} d(u, B), \sup _{v \in B} d(v, A)\right\} .
$$

The following two lemmas which can be found in [5] or [16] are useful for our main results.

Lemma 2.1 ([5]) Let $(X, d)$ be a metric space. If $A, B \in C B(X)$ and $a \in A$, then, for each $\epsilon>0$, there exists $b \in B$ such that

$$
d(a, b) \leq H(A, B)+\epsilon .
$$

Lemma 2.2 ([16]) Let $\left\{A_{n}\right\}$ be a sequence of sets in $C B(X)$, and suppose $\lim _{n \rightarrow \infty} H\left(A_{n}, A_{0}\right)=$ 0 where $A_{0} \in C B(X)$. Then if $x_{n} \in A_{n}, n=1,2,3, \ldots$, and if $\lim _{n \rightarrow \infty} x_{n}=x_{0}$, it follows that $x_{0} \in A_{0}$.

Definition 2.3 Let $T: X \rightarrow 2^{X}$ be a mapping. A point $x \in X$ is said to be a fixed point of $T$ if $x \in T x$.

Definition 2.4 A preorder is a binary relation $\leq$ in a set $X$ which satisfies the followings conditions:

(1) $x \leq x$ (reflexivity);

(2) if $x \leq y$ and $y \leq z$, then $x \leq z$ (transitivity) for all $x, y \in X$.

A set with a preorder $\leq$ is called a preordered set.

For $x, y \in X$, we write

$$
x<y \quad \text { if } x \leq y \text { and } x \neq y .
$$


A partial ordering in a set $X$ is a preordered $\leq$ in $X$ with the additional property:

If $x \leq y$ and $y \leq x, \quad$ then $x=y$ (antisymmetry).

A set together with a definite partial ordering is called a partially ordered set. Let $(X, \leq)$ be a partially ordered set. In 2010, Beg and Butt [8] defined relations between two sets. For $A, B \subset X$, the relations $\leq^{(\mathrm{I})}$ and $\leq^{(\mathrm{II})}$ between $A$ and $B$ are defined as follows:

(1) $A \leq^{(\mathrm{I})} B$ if $a \leq b$ for all $a \in A$ and $b \in B$.

(2) $A \leq{ }^{\text {(II) }} B$ if for each $a \in A$ there exists $b \in B$ such that $a \leq b$.

Note that if $A$ is a nonempty subset of $X$ with $A \leq^{(\mathrm{I})} A$, then $A$ is singleton.

Next, we define two types of monotone mappings by using the relations $\leq^{(\mathrm{I})}$ and $\leq^{(\mathrm{II})}$.

Definition 2.5 Let $(X, d)$ be a metric space endowed with a partial order $\leq$ and $T: X \rightarrow$ $C B(X)$. Then $T$ is said to be

(i) monotone nondecreasing of type (I) if

$$
x, y \in X, \quad x<y \quad \Rightarrow \quad T x \leq^{(\mathrm{I})} T y
$$

(ii) monotone nondecreasing of type (II) if

$$
x, y \in X, \quad x \leq y \quad \Rightarrow \quad T x \leq^{(I I)} T y .
$$

The concept of monotonicity of type (II) was first introduced by Fujimoto [21]. Instead of monotonicity of type (II), he used the notion of isotone or ordered-increasing upward. He proved the following fixed point theorem known as the Fujimoto-Tarski fixed point theorem.

Theorem 2.6 ([21]) Let $(X, \leq)$ be a complete lattice and $F: X \rightarrow 2^{X}\{\emptyset\}$ a multi-valued mapping. If $F$ satisfies the following two conditions:

(1) $F$ is isotone, that is, ( $F$ is ordered-increasing upward) if $x \leq y$, then for any $z \in F(x)$ there is a $w \in F(y)$ such that $z \leq w$.

(2) $S F(x)=\{z \in X: z \leq u$ for some $u \in F(x)\}$ is an inductively ordered set for each $x \in X$.

Then $F$ has a fixed point.

He also applied this result to study solvability of vector-complementarity problems. In [4], Li applied this theorem to investigate the existence of generalized and extended Nash equilibria of non-monetized, non-cooperative games on chain-complete lattices.

Very recently, Li [4] extended Theorem 2.6 to the following theorems.

Theorem 2.7 Let $(P, \leq)$ be a chain-complete poset and let $P: P \rightarrow 2^{P} \backslash\{\emptyset\}$ be a set-valued mapping. If $F$ satisfies the following three conditions:

(A1) $F$ is order-increasing upward;

(A2) $(S F(x), \leq)$ is an inductively ordered set, for each $x \in P$;

(A3) There is a $y$ in $P$ with $y \leq u$ for some $u \in F(y)$.

Then $F$ has a fixed point.

He also used this theorem to study the existence of generalized and extended Nash equilibrium problems. 
It is easy to see that monotone nondecreasing of type (I) is of type (II) but the converse is not true as seen in the following example.

Example 2.8 Let $X=[0, \infty)$ with the usual relation $\leq$ defined on it. Let $T: X \rightarrow 2^{X}$ be defined by

$$
T x=[0, x], \quad x \in X
$$

It is easy to see that $T$ is monotone nondecreasing of type (II) but not type (I).

\section{Main results}

We first prove the existence theorem for monotone multi-valued mappings of type (II) involving the delta distance. Throughout this paper, we use $\mathcal{J}$ to denote the class function $\varphi:[0, \infty) \rightarrow[0,1)$ such that $\lim _{r \rightarrow t^{+}} \sup \varphi(r)<1$ for each $t \in[0, \infty)$.

Theorem 3.1 Let $(X, d)$ be a complete metric space endowed with a partial ordered $\leq$ and $T: X \rightarrow C B(X)$ be multi-valued mapping. Suppose that:

(1) $T$ is monotone of type (II).

(2) There exists $x_{0} \in X$ such that $x_{0} \leq^{\text {(II) }} T x_{0}$.

(3) For each sequence $\left\{x_{n}\right\}$ such that $x_{n} \leq x_{n+1}$ for all $n \in \mathbb{N}$ and $x_{n}$ converges to $x$, for some $x \in X$, then $x_{n} \leq x$ for all $n \in \mathbb{N}$.

(4) There exists a function $\varphi \in \mathcal{J}$ such that

$$
\delta(T x, T y) \leq \varphi(d(x, y))(d(x, y)) \quad \text { for all } x, y \in X \text { with } x \leq y .
$$

Then there exists $x \in X$ such that $x \in T x$.

Proof By assumption (2), there exists $x_{1} \in T x_{0}$ such that $x_{0} \leq x_{1}$. Moreover, by monotonicity of $T$, we have $T x_{0} \leq T x_{1}$ i.e. there exists $x_{2} \in T x_{1}$ such that $x_{1} \leq x_{2}$. By (4), we have

$$
d\left(x_{1}, x_{2}\right) \leq \delta\left(T x_{0}, T x_{1}\right) \leq \varphi\left(d\left(x_{0}, x_{1}\right)\right) d\left(x_{0}, x_{1}\right)<d\left(x_{0}, x_{1}\right) .
$$

By induction, we obtain a sequence $\left\{x_{n}\right\}$ in $X$ with the property that $x_{n+1} \in T x_{n}, x_{n} \leq x_{n+1}$ and

$$
d\left(x_{n}, x_{n+1}\right)<d\left(x_{n-1}, x_{n}\right) \quad \text { for all } n \in \mathbb{N} .
$$

We see that $\left\{d\left(x_{n}, x_{n+1}\right)\right\}$ is strictly decreasing and bounded below so

$$
\lim _{n \rightarrow \infty} d\left(x_{n}, x_{n+1}\right)=r \geq 0 .
$$

Suppose $r>0$. Then

$$
d\left(x_{n}, x_{n+1}\right) \leq \delta\left(T x_{n-1}, T x_{n}\right) \leq \varphi\left(d\left(x_{n-1}, x_{n}\right)\right) d\left(x_{n-1}, x_{n}\right) .
$$

Therefore

$$
\begin{aligned}
r & =\underset{n}{\limsup } d\left(x_{n}, x_{n+1}\right) \leq \limsup _{n} \varphi\left(d\left(x_{n-1}, x_{n}\right)\right) \limsup _{n} d\left(x_{n-1}, x_{n}\right) \\
& <\underset{n}{\lim \sup } d\left(x_{n-1}, x_{n}\right)=r
\end{aligned}
$$


which is a contradiction. We conclude that $r=0$ i.e., $\lim _{n \rightarrow \infty} d\left(x_{n}, x_{n+1}\right)=0$. We will show that $\left\{x_{n}\right\}$ is a Cauchy sequence. To show this, suppose not. Then there exist $\epsilon>0$ and integers $m_{k}, n_{k} \in \mathbb{N}$ such that $m_{k}>n_{k} \geq k$ and

$$
d\left(x_{n_{k}}, x_{m_{k}}\right) \geq \epsilon \text { for } k=0,1,2, \ldots
$$

Also choosing $m_{k}$ as small as possible, it may be assumed that

$$
d\left(x_{m_{k}-1}, x_{n_{k}}\right)<\epsilon .
$$

Hence, for each $k \in \mathbb{N}$, we have

$$
\begin{aligned}
\epsilon & \leq d\left(x_{m_{k}}, x_{n_{k}}\right) \leq d\left(x_{m_{k}}, x_{m_{k}-1}\right)+d\left(x_{m_{k}-1}, x_{n_{k}}\right) \\
& <d\left(x_{m_{k}-1}, x_{m_{k}}\right)+\epsilon .
\end{aligned}
$$

Since $\lim _{k \rightarrow \infty} d\left(x_{m_{k}-1}, x_{m_{k}}\right)=0$, we have $\lim _{k \rightarrow \infty} d\left(x_{m_{k}} x_{n_{k}}\right)=\epsilon$. By transitivity of $\leq$, we have $x_{n_{k}} \leq x_{m_{k}}$. By using the triangle inequality and assumption (4), we have

$$
\begin{aligned}
d\left(x_{m_{k}}, x_{n_{k}}\right) & \leq d\left(x_{m_{k}}, x_{m_{k}+1}\right)+d\left(x_{m_{k+1}}, x_{n_{k}+1}\right)+d\left(x_{n_{k+1}}, x_{n_{k}}\right) \\
& \leq d\left(x_{m_{k}}, x_{m_{k}+1}\right)+\delta\left(\left(T x_{m_{k}}, T x_{n_{k}}\right)\right)+d\left(x_{n_{k+1}}, x_{n_{k}}\right) \\
& \leq d\left(x_{m_{k}}, x_{m_{k}+1}\right)+\varphi\left(d\left(x_{m_{k}}, x_{n_{k}}\right)\right) d\left(x_{m_{k}}, x_{n_{k}}\right)+d\left(x_{n_{k+1}}, x_{n_{k}}\right) .
\end{aligned}
$$

Letting $k \rightarrow \infty$ and using the property of $\varphi$, we obtain

$$
\begin{aligned}
\epsilon & \leq 0+\limsup _{k \rightarrow \infty}\left(\varphi\left(d\left(x_{m_{k}}, x_{n_{k}}\right)\right) d\left(x_{m_{k}}, x_{n_{k}}\right)\right)+0 \\
& =\limsup _{k \rightarrow \infty} \varphi\left(d\left(x_{m_{k}}, x_{n_{k}}\right)\right) \limsup _{k \rightarrow \infty} d\left(x_{m_{k}}, x_{n_{k}}\right) \\
& <\limsup _{k \rightarrow \infty} d\left(x_{m_{k}}, x_{n_{k}}\right) \\
& =\epsilon,
\end{aligned}
$$

which is a contradiction. Hence $\left\{x_{n}\right\}$ is a Cauchy sequence in $X$. Since $X$ is complete, there exists $x \in X$ such that $\lim _{n \rightarrow \infty} x_{n}=x$. Moreover, we have $x_{n} \leq x$ by (3) and

$$
\begin{aligned}
d(x, T x) & \leq d\left(x, x_{n+1}\right)+d\left(x_{n+1}, T x_{n}\right)+\delta\left(T x_{n}, T x\right) \\
& \leq d\left(x, x_{n+1}\right)+\varphi\left(d\left(x_{n}, x\right)\right) d\left(x_{n}, x\right) \\
& <d\left(x, x_{n+1}\right)+d\left(x_{n}, x\right) .
\end{aligned}
$$

Taking $n \rightarrow \infty$, we obtain $d(x, T x)=0$. That is, $x \in T x$.

In the next theorem, we prove a fixed point theorem of monotone multi-valued mapping of type (I) under some contraction conditions involving the Hausdorff distance.

Theorem 3.2 Let $(X, d)$ be a complete metric space endowed with a partial ordered $\leq$ and $T: X \rightarrow C B(X)$ be multi-valued mapping. Suppose that: 
(1) $T$ is monotone nondecreasing of type (I).

(2) There exists $x_{0} \in X$ such that $x_{0} \leq{ }^{(I I)} T x_{0}$.

(3) For each sequence $\left\{x_{n}\right\}$ such that $x_{n} \leq x_{n+1}$ for all $n \in \mathbb{N}$ and $x_{n}$ converges to $x$, for some $x \in X$, then $x_{n} \leq x$ for all $n \in \mathbb{N}$.

(4) There exists a function $\varphi \in \mathcal{J}$ such that

$$
H(T x, T y) \leq \varphi(d(x, y))(d(x, y)) \quad \text { for all } x, y \in X \text { with } x \leq y .
$$

Then there exists $x \in X$ such that $x \in T x$.

Proof Suppose that $T$ has no fixed point, i.e.,

$$
d(x, T x)>0 \text { for all } x \in X \text {. }
$$

By assumption (4), for any $t>0$, there exist $M(t)>0$ and $\delta(t)>0$ such that

$$
\varphi(r) \leq M(t)<1 \quad \text { for all } r \text { with } t<r<t+\delta(t) .
$$

Since $x_{0} \leq^{(I I)} T x_{0}$, there exists $x_{1} \in T x_{0}$ such that $x_{0} \leq x_{1}$. By monotonicity of $T$, we have $T x_{0} \leq^{(\mathrm{I})} T x_{1}$. Put $t_{1}=d\left(x_{1}, T x_{1}\right)$. Note that $d\left(x_{1}, T x_{1}\right) \leq d(x, y)$ for all $y \in T x_{1}$. We consider the following cases:

Case (I): $d\left(x_{1}, T x_{1}\right)<d\left(x_{1}, y\right)$ for all $y \in T x_{1}$. Choose $d\left(t_{1}\right)$ such that

$$
d\left(t_{1}\right)<\min \left\{\delta\left(t_{1}\right),\left(\frac{1}{M\left(t_{1}\right)}-1\right) t_{1}\right\}
$$

and then put

$$
\epsilon\left(x_{1}\right)=\min \left\{\frac{d\left(t_{1}\right)}{t_{1}}, 1\right\} .
$$

Then there exists $x_{2} \in T x_{1}$ such that

$$
d\left(x_{1}, x_{2}\right)<d\left(x_{1}, T x_{1}\right)+\epsilon\left(x_{1}\right) d\left(x_{1}, T x_{1}\right)=\left(1+\epsilon\left(x_{1}\right)\right) d\left(x_{1}, T x_{1}\right) .
$$

By the hypothesis that $T$ has no fixed point, we have $x_{1} \neq x_{2}$ so $x_{1}<x_{2}$ and by (4), we obtain

$$
d\left(x_{2}, T x_{2}\right) \leq H\left(T x_{1}, T x_{2}\right) \leq \varphi\left(d\left(x_{1}, x_{2}\right)\right) d\left(x_{1}, x_{2}\right) .
$$

This implies

$$
\begin{aligned}
d\left(x_{1}, T x_{1}\right)-d\left(x_{2}, T x_{2}\right) & \geq d\left(x_{1}, T x_{1}\right)-\varphi\left(d\left(x_{1}, x_{2}\right)\right) d\left(x_{1}, x_{2}\right) \\
& >\frac{1}{1+\epsilon\left(x_{1}\right)} d\left(x_{1}, x_{2}\right)-\varphi\left(d\left(x_{1}, x_{2}\right)\right) d\left(x_{1}, x_{2}\right) \\
& =\left\{\frac{1}{1+\epsilon\left(x_{1}\right)}-\varphi\left(d\left(x_{1}, x_{2}\right)\right)\right\} d\left(x_{1}, x_{2}\right) .
\end{aligned}
$$


By (3.3) and (3.4) we obtain

$$
\begin{aligned}
t_{1} & =d\left(x_{1}, T x_{1}\right)<d\left(x_{1}, x_{2}\right)<d\left(x_{1}, T x_{1}\right)+\epsilon\left(x_{1}\right) d\left(x_{1}, T x_{1}\right) \\
& \leq t_{1}+d\left(t_{1}\right)<t_{1}+\delta\left(t_{1}\right) .
\end{aligned}
$$

This implies by (3.1) that $\varphi\left(d\left(x_{1}, x_{2}\right)\right) \leq M\left(t_{1}\right)<1$. Since

$$
\epsilon\left(x_{1}\right) \leq \frac{d\left(t_{1}\right)}{t_{1}}<\frac{1}{M\left(t_{1}\right)}-1
$$

we have $\frac{1}{1+\epsilon\left(x_{1}\right)}>M\left(t_{1}\right)$. Hence

$$
\frac{1}{1+\epsilon\left(x_{1}\right)}-\varphi\left(d\left(x_{1}, x_{2}\right)\right)>0
$$

It follows from (3.5) that $d\left(x_{2}, T x_{2}\right)<d\left(x_{1}, T x_{1}\right)$.

Case (II): $d\left(x_{1}, T x_{1}\right)=d\left(x_{1}, x_{2}\right)$ for some $x_{2} \in T x_{1}$. Since $T x_{0} \leq^{(\mathrm{I})} T x_{1}$, we have $x_{1} \leq x_{2}$. By (4), we have

$$
\begin{aligned}
d\left(x_{1}, T x_{1}\right)-d\left(x_{2}, T x_{2}\right) & \geq d\left(x_{1}, T x_{1}\right)-H\left(T x_{1}, T x_{2}\right) \\
& \geq d\left(x_{1}, T x_{1}\right)-\varphi\left(d\left(x_{1}, x_{2}\right)\right) d\left(x_{1}, x_{2}\right) \\
& =\left\{1-\varphi\left(d\left(x_{1}, x_{2}\right)\right)\right\} d\left(x_{1}, x_{2}\right)>0 .
\end{aligned}
$$

Therefore $d\left(x_{2}, T x_{2}\right)<d\left(x_{1}, T x_{1}\right)$. Next, let $t_{2}=d\left(x_{2}, T x_{2}\right)$. Then $d\left(x_{2}, T x_{2}\right) \leq d\left(x_{2}, y\right)$ for all $y \in T x_{2}$. Again we consider the following two cases:

Case (A): $d\left(x_{2}, T x_{2}\right)<d\left(x_{2}, y\right)$ for all $y \in T x_{2}$. For $\delta\left(t_{2}\right)$ and $M\left(t_{2}\right)$, choose $d\left(t_{2}\right)$ with

$$
d\left(t_{2}\right)<\min \left\{\delta\left(t_{2}\right),\left(\frac{1}{M\left(t_{2}\right)}-1\right) t_{1}\right\}
$$

and set

$$
\epsilon\left(x_{2}\right)=\min \left\{\frac{d\left(t_{2}\right)}{t_{2}}, \frac{1}{2}, \frac{t_{1}}{t_{2}}-1\right\} .
$$

By using the argument as above, we obtain $x_{3} \in T x_{2}$ such that

$$
d\left(x_{2}, x_{3}\right)<\left(1+\epsilon\left(x_{2}\right)\right) d\left(x_{2}, T x_{2}\right)
$$

and

$$
d\left(x_{2}, T x_{2}\right)-d\left(x_{3}, T x_{3}\right) \geq\left\{\frac{1}{1+\epsilon\left(x_{2}\right)}-\varphi\left(d\left(x_{2}, x_{3}\right)\right)\right\} d\left(x_{2}, x_{3}\right)
$$

$>0$.

Hence $d\left(x_{3}, T x_{3}<d\left(x_{2}, T x_{2}\right)\right)$. From $\epsilon\left(x_{2}\right) \leq \frac{t_{1}}{t_{2}}-1$, it follows that

$$
d\left(x_{2}, x_{3}\right)<\left(1+\epsilon\left(x_{2}\right)\right) d\left(x_{2}, T x_{2}\right) \leq d\left(x_{1}, T x_{1}\right) \leq d\left(x_{1}, x_{2}\right) .
$$


Case (B): $d\left(x_{2}, T x_{2}\right)=d\left(x_{2}, x_{3}\right)$ for some $x_{3} \in T x_{2}$. Using the same method as above, we can show that

$$
d\left(x_{2}, T x_{2}\right)-d\left(x_{3}, T x_{3}\right) \geq\left\{1-\varphi\left(d\left(x_{2}, x_{3}\right)\right)\right\} d\left(x_{2}, x_{3}\right)>0
$$

and

$$
d\left(x_{2}, x_{3}\right)=d\left(x_{2}, T x_{2}\right)<d\left(x_{1}, T x_{1}\right) \leq d\left(x_{1}, x_{2}\right) .
$$

Hence, $d\left(x_{3}, T x_{3}\right)<d\left(x_{2}, T x_{2}\right)$ and $d\left(x_{2}, x_{3}\right)<d\left(x_{1}, x_{2}\right)$. By continuing in this way, we can construct a sequence $\left\{x_{n}\right\}$ in $X$ with $x_{n+1} \in T x_{n}, x_{n} \leq x_{n+1}$ for all $n \in \mathbb{N}$ such that $\left\{d\left(x_{n}, x_{n+1}\right)\right\}$ and $\left\{d\left(x_{n}, T x_{n}\right)\right\}$ are decreasing sequences of positive numbers and

$$
d\left(x_{n}, T x_{n}\right)-d\left(x_{n+1}, T x_{n+1}\right) \geq\left\{\frac{1}{1+\gamma\left(x_{n}\right)}-\varphi\left(d\left(x_{n}, x_{n+1}\right)\right)\right\} d\left(x_{n}, x_{n+1}\right),
$$

where $\gamma\left(x_{n}\right)$ is a real number with $0 \leq \gamma\left(x_{n}\right) \leq \frac{1}{n}(n=1,2, \ldots)$. Since $\left\{d\left(x_{n}, x_{n+1}\right)\right\}$ is decreasing, there exists $t \in[0, \infty)$ such that $\lim _{n \rightarrow \infty} d\left(x_{n}, x_{n+1}\right)=t$. By the property of $\varphi$, we obtain

$$
\lim _{n \rightarrow \infty} \sup \varphi\left(d\left(x_{n}, x_{n+1}\right)\right)<1
$$

Putting $a_{n}=\frac{1}{1+\gamma\left(x_{n}\right)}-\varphi\left(d\left(x_{n}, x_{n+1}\right)\right)$, we have

$$
\lim _{n \rightarrow \infty} \inf a_{n} \geq \lim _{n \rightarrow \infty} \frac{1}{1+\gamma\left(x_{n}\right)}-\lim _{n \rightarrow \infty} \sup \varphi\left(d\left(x_{n}, x_{n+1}\right)\right)>0 .
$$

This implies by (3.7) that there exists $b>0$ such that

$$
d\left(x_{n}, T x_{n}\right)-d\left(x_{n+1}, T x_{n+1}\right) \geq b d\left(x_{n}, x_{n+1}\right)
$$

for large enough $n$. Since $\left\{d\left(x_{n}, T x_{n}\right)\right\}$ is decreasing, it is convergent. It follows that

$$
\begin{aligned}
d\left(x_{n}, x_{m}\right) & \leq \sum_{j=n}^{m-1} d\left(x_{j}, x_{j+1}\right) \\
& \leq \frac{1}{b} \sum_{j=n}^{m-1}\left\{d\left(x_{j}, T x_{j}\right)-d\left(x_{j+1}, T x_{j+1}\right)\right\} \\
& =\frac{1}{b}\left\{d\left(x_{n}, T x_{n}\right)-d\left(x_{m}, T x_{m}\right)\right\} \rightarrow 0
\end{aligned}
$$

as $m, n \rightarrow \infty$. Hence $\left\{x_{n}\right\}$ is Cauchy. So $\left\{x_{n}\right\}$ converges to some $x \in X$. By (3), we obtain $x_{n} \leq x$ for all $n \in \mathbb{N}$. By (4), we get

$$
H\left(T x, T x_{n}\right) \leq \varphi\left(d\left(x, x_{n}\right)\right) d\left(x, x_{n}\right) \leq d\left(x, x_{n}\right)
$$

Hence $\lim _{n \rightarrow \infty} H\left(T x, T x_{n}\right)=0$. Since $x_{n+1} \in T x_{n}$ and $\left\{x_{n+1}\right\}$ converges to $x$, it follows from Lemma 2.2 that $x \in T x$. This contradicts that $T$ has no fixed point. This complete the proof. 
Corollary 3.3 Let $(X, d)$ be a complete metric space endowed with a partial ordered $\leq$ and $T: X \rightarrow C B(X)$ be multi-valued mapping. Suppose that:

(1) $T$ is monotone of type (II).

(2) There exists $x_{0} \in X$ such that $x_{0} \leq$ (II) $T x_{0}$.

(3) For each sequence $\left\{x_{n}\right\}$ such that $x_{n} \leq x_{n+1}$ for all $n \in \mathbb{N}$ and $x_{n}$ converges to $x$, for some $x \in X$, then $x_{n} \leq x$ for all $n \in \mathbb{N}$.

(4) There exists $k \in(0,1)$ such that

$$
\delta(T x, T y) \leq k(d(x, y)) \text { for each } x \leq y .
$$

Then there exists $x \in X$ such that $x \in T x$.

Proof We denote $\varphi(r)=k$ for all $r \in(0, \infty)$, so, for any $t \in[0, \infty)$,

$$
\lim _{r \rightarrow t+} \sup \varphi(r)=k<1 .
$$

Moreover, for each $x, y \in X$ with $x \leq y$, we obtain

$$
\delta(T x, T y) \leq k(d(x, y))=\varphi(d(x, y))(d(x, y)) .
$$

By Theorem 3.2, we obtain the desired result.

Remark 3.4 The reader interested in common fixed point results of multi-valued mappings taking closed values in ordered generalized metric spaces is referred to [6].

Example 3.5 Let $X=\left\{\frac{1}{2}, \frac{1}{4}, \ldots, \frac{1}{2^{n}}, \ldots\right\} \cup\{0,1\}, d(x, y)=|x-y|$, for $x, y \in X$; then $X$ is a complete metric space. Define a relation $\leq$ by

$$
x \leq y \quad \text { if } \frac{y}{x} \in \mathbb{N} \text { or } x=y=0 .
$$

It is easy to check that this relation is a partially ordered. Note that $0 \not 1$.

Define the mapping $T: X \rightarrow C B(X)$ by

$$
T(x)= \begin{cases}\left\{\frac{1}{2^{2 n+1}}, \frac{1}{2^{2 n}}\right\} & \text { if } x=\frac{1}{2^{n}}, n=1,2, \ldots, \\ \{0\} & \text { if } x=0, \\ \left\{\frac{1}{4}, \frac{1}{2}, 1\right\} & \text { if } x=1 .\end{cases}
$$

Clearly, $T$ is increasing of type (I). Moreover, if $\frac{1}{2^{n}} \leq \frac{1}{2^{m}}$,

$$
\begin{aligned}
H\left(T\left(\frac{1}{2^{n}}\right), T\left(\frac{1}{2^{m}}\right)\right) & =H\left(\left\{\frac{1}{2^{2 n+1}}, \frac{1}{2^{2 n}}\right\},\left\{\frac{1}{2^{2 m+1}}, \frac{1}{2^{2 m}}\right\}\right) \\
& =\left|\frac{1}{2^{2 m+1}}-\frac{1}{2^{2 n+1}}\right| \\
& =\frac{1}{2}\left|\frac{1}{2^{2 m}}-\frac{1}{2^{2 n}}\right| \\
& <\frac{1}{2}\left|\frac{1}{2^{m}}-\frac{1}{2^{n}}\right|=\frac{1}{2} d\left(\frac{1}{2^{n}}, \frac{1}{2^{m}}\right)
\end{aligned}
$$


and

$$
\begin{aligned}
H\left(T(0), T\left(\frac{1}{2^{n}}\right)\right) & =H\left(\{0\},\left\{\frac{1}{2^{2 n+1}}, \frac{1}{2^{2 n}}\right\}\right) \\
& =\frac{1}{2^{2 n+1}} \\
& <\frac{1}{2^{n+1}}=\frac{1}{2} d\left(0, \frac{1}{2^{n}}\right) .
\end{aligned}
$$

Moreover,

$$
\begin{aligned}
H(T(0), T(1)) & =H\left(\{0\},\left\{\frac{1}{4}, \frac{1}{2}, 1\right\}\right) \\
& =\max \left\{\frac{1}{4}, 1\right\}=1 \\
& >\varphi(d(0,1)) d(0,1) \quad \text { for any } \varphi \in \mathcal{J} .
\end{aligned}
$$

Thus $T$ is not a contraction mapping. So Nadler's theorem and Mizoguchi and Takahashi's theorem [16] cannot guarantee the existence of its fixed point. However, $T$ satisfies all conditions of Theorem 3.2. So it has a fixed point and we note that 0 and 1 are its fixed points.

\section{Some applications}

In this section, we will recall some concepts of generalized and extended Nash equilibria of non-monetized, non-cooperative game which are defined in $[3,4]$ and we point out that our main result can be applied to prove some existence theorems for generalized and extended Nash equilibria problems.

Definition 4.1 Let $n$ be a positive integer greater than 1. An $n$-person non-monetized non-cooperative game consists of the following elements:

1. the set of $n$ players, which is denoted by $N=\{1,2, \ldots, n\}$;

2. the collection of $n$ strategy sets $\left\{S_{1}, S_{2}, \ldots, S_{n}\right\}$, for the $n$ player, respectively, such that $\left(S_{i}, \succeq_{i}\right)$ is a chain-complete poset, for every player $i=1,2, \ldots, n$, with notation $S=S_{1} \times S_{2} \times \cdots \times S_{n}$

3. the outcome space $\left(U, \succeq^{U}\right)$ that is a poset;

4. the $n$ payoff function $P_{1}, P_{2}, \ldots, P_{n}$, where $P_{i}$ is the payoff function for player $i$ that is a mapping from $S_{1} \times S_{2} \times \cdots \times S_{n}$ to the poset $\left(U, \succeq^{U}\right)$, for $i=1,2, \ldots, n$. We denote $P=\left\{P_{1}, P_{2}, \ldots, P_{n}\right\}$.

This game is denoted by $\Gamma=(N, S, P, U)$.

The rule to play in an $n$-person non-monetized, non-cooperative game $\Gamma=(N, S, P, U)$ is that when all the $n$ players $1,2, \ldots, n$ simultaneously and independently choose their own strategies $x_{1}, x_{2}, \ldots, x_{n}$ where $x_{i} \in S_{i}$, for $i=1,2, \ldots, n$, then player $i$ will receive his or her utility (payoff) $P_{i}\left(x_{1}, x_{2}, \ldots, x_{n}\right) \in U$. For any $x=\left(x_{1}, x_{2}, \ldots, x_{n}\right) \in S$, and for every given $i=1,2, \ldots, n$, as usual, we denote

$$
x_{-i}:=\left(x_{1}, x_{2}, \ldots, x_{i-1}, x_{i+1}, \ldots, x_{n}\right) \quad \text { and } \quad S_{-i}:=S_{1} \times S_{2} \times \cdots \times S_{i-1} \times S_{i+1} \times \cdots \times S_{n} \text {. }
$$


Then $x_{-i} \in S_{-i}$. We use the following notations: $x=\left(x_{i}, x_{-i}\right)$ and $P_{i}\left(S_{i}, x_{-i}\right)=\left\{P_{i}\left(t_{i}, x_{-i}\right): t_{i} \in\right.$ $\left.S_{i}\right\}$.

Next, we recall the concept of generalized and extended Nash equilibrium of nonmonetized, non-cooperative games on preordered sets.

Definition 4.2 In an $n$-person non-monetized, non-cooperative game $\Gamma=(N, S, P, U)$, a selection of strategies $\hat{x}=\left(\hat{x}_{1}, \hat{x}_{2}, \ldots, \hat{x}_{n}\right) \in\left(S_{1} \times S_{2} \times \cdots \times S_{n}\right)$ is called

1. a generalized Nash equilibrium of this game, if, for every $i=1,2, \ldots, n$, the following order inequality holds:

$$
P_{i}\left(x_{i}, \hat{x}_{-i}\right) \preceq^{U} P_{i}\left(\hat{x}_{i}, \hat{x}_{-i}\right) \quad \text { for all } x_{i} \in S_{i} ;
$$

2. an extended Nash equilibrium of this game, if, for every $i=1,2, \ldots, n$, the following order inequality holds:

$$
P_{i}\left(x_{i}, \hat{x}_{-i}\right) \nsucc^{U} P_{i}\left(\hat{x}_{i}, \hat{x}_{-i}\right) \quad \text { for all } x_{i} \in S_{i} .
$$

We note that the conditions (A1) and (A2) of Theorem 2.7 are those (1) and (3) of Theorem 3.1, respectively, while we have no assumption (A2) in Theorem 2.7. However, we need to assume conditions (3) and (4) because the studied space of our main result is more general than that of Theorem 2.7. We observe that in our study, we need some contractive condition on a mapping $T: X \rightarrow C B(X)$.

By using the same as the application of Theorem 2.7, under some modifications of the problem setting, Theorem 3.1 can be applied to prove the existence of generalized and extended Nash equilibria of non-monetized, non-cooperative game on a partially ordered metric space.

Competing interests

The authors declare that they have no competing interests.

\section{Authors' contributions}

All authors contributed equally to the writing of this paper. All authors read and approved the final manuscript.

\section{Acknowledgements}

This work was supported by Chiang Mai University, Chiang Mai, Thailand.

Received: 4 September 2013 Accepted: 16 April 2014 Published: 06 May 2014

References

1. Aubin, JP: Mathematical Methods of Games and Economic Theory. North-Holland, Amsterdam (1979)

2. Bohnenblust, S, Karlin, S: Contributions to the Theory of Games. Princeton University Press, Princeton (1950)

3. Carl, S, Heikkila, S: Fixed Point Theory in Ordered Sets and Applications: From Differential and Integral Equations to Game Theory. Springer, New York (2010)

4. Li, JL: Several extensions of the Abian-Brown fixed point theorem and their applications to extended and generalized Nash equalibria on chain-complete posets. J. Math. Anal. Appl. 409, 1084-1094 (2014)

5. Nadler, S: Multi-valued contraction mappings. Pac. J. Math. 20(2), 475-488 (1969)

6. Abbas, M, Khan, AR, Nazir, T: Common fixed point of multivalued mappings in ordered generalized metric spaces. Filomat 26(5), 1045-1053 (2012)

7. Assad, NA, Kirk, WA: Fixed point theorems for set-valued mappings of contractive type. Pac. J. Math. 43, 553-562 (1972)

8. Beg, I, Butt, AR: Common fixed point for generalized set valued contractions satisfying an implicit relation in partially ordered metric spaces. Math. Commun. 15, 65-75 (2010)

9. Beg, I, Butt, AR: Fixed point for set valued mappings satisfying an implicit relation in partially ordered metric spaces. Nonlinear Anal. 71, 3699-3704 (2009)

10. Bhaskar, TG, Laskhmikantham, V: Fixed point theorems in partially ordered metric spaces and applications. Nonlinear Anal. 65(7), 1379-1393 (2006) 
11. Ciric, LB: Common fixed point theorems for multi-valued mappings. Demonstr. Math. 39(2), 419-428 (2006)

12. Ciric, LB: Fixed point theorems for set-valued non-self mappings. Math. Balk. 20(2), 207-217 (2006)

13. Ciric, LB: Multi-valued nonlinear contraction mappings. Nonlinear Anal. 71, 2716-2723 (2009)

14. Ciric, LB, Ume, JS: Some common fixed point theorems for weakly compatible mappings. J. Math. Anal. Appl. 314(2), 488-499 (2006)

15. Feng, Y, Liu, S: Fixed point theorems for multi-valued contractive mappings and multi-valued Caristi type mappings. J. Math. Anal. Appl. 317, 103-112 (2006)

16. Mizoguchi, N, Takahashi, W: Fixed point theorems for multivalued mappings on complete metric spaces. J. Math. Anal. Appl. 141, 177-188 (1989)

17. Naidu, SVR: Fixed point theorems for a board class of multimaps. Nonlinear Anal. 52, 961-969 (2003)

18. Reich, S: Fixed points of contractive functions. Boll. Unione Mat. Ital. 5, 26-42 (1972)

19. Beg, I, Latif, A: Common fixed point and coincidence point of generalized contractions in ordered metric spaces. Fixed Point Theory Appl. 2012, 229 (2012)

20. Daffer, PZ, Kaneko, H: Fixed points of generalized contractive multi-valued mappings. J. Math. Anal. Appl. 192, 655-666 (1995)

21. Fujimoto, T: An extension of Tarski's fixed point theorem and its applications to isotone complementarity problems. Math. Program. 28, 116-118 (1984)

22. Klim, D, Wardowski, D: Fixed point theorems for set-valued contractions in complete metric spaces. J. Math. Anal. Appl. 334, 132-139 (2007)

23. Ran, ACM, Reurings, MCB: A fixed point theorem in partially ordered sets and some applications to matrix equations. Proc. Am. Math. Soc. 132(5), 1435-1443 (2003)

24. Nieto, JJ, Rodriguez-Lopez, R: Contractive mapping theorems in partially ordered sets and applications to ordinary differential equations. Order 22, 223-239 (2005)

10.1186/1687-1812-2014-110

Cite this article as: Tiammee and Suantai: Fixed point theorems for monotone multi-valued mappings in partially ordered metric spaces. Fixed Point Theory and Applications 2014, 2014:110

\section{Submit your manuscript to a SpringerOpen ${ }^{\ominus}$ journal and benefit from:}

- Convenient online submission

- Rigorous peer review

- Immediate publication on acceptance

- Open access: articles freely available online

- High visibility within the field

- Retaining the copyright to your article 